\title{
Mechanism of protracted metabolic effects of fatty acid acylated insulin, NN304, in dogs: retention of NN304 by albumin
}

\author{
M. Hamilton-Wessler ${ }^{1}$, M. Ader ${ }^{1}$, M. Dea ${ }^{1}$, D. Moore ${ }^{1}$, P. N. Jorgensen ${ }^{2}$, J. Markussen ${ }^{2}$, R. N. Bergman \\ ${ }^{1}$ Department of Physilogy and Biophysics, University of Southern California School of Medicine, Los Angeles, California, USA \\ ${ }^{2}$ Novo Research Institute, Novo Nordisk, Bagsvaerd, Denmark
}

\section{Abstract}

Aims/hypothesis. The provision of stable, reproducible basal insulin is crucial to diabetes management. This study in dogs examined the metabolic effects and interstitial fluid (ISF) profiles of fatty acid acylated insulin, Lys ${ }^{\mathrm{B} 29}$-tetradecanoyl, des-(B30) human insulin (NN304).

Methods. Euglycaemic clamps were carried out under inhalant anaesthesia during equimolar intravenous infusions (3.6 $\mathrm{pmol} \cdot \mathrm{min}^{-1} \cdot \mathrm{kg}^{-1}$ for $480 \mathrm{~min}$ ) of human insulin or NN304 ( $n=8$ per group).

Results. Steady-state total NN304 (albumin-bound and unbound) was considerably higher in plasma compared with human insulin $(1895 \pm 127$ vs $181 \pm 10 \mathrm{pmol} / \mathrm{l}, p<0.001)$ and increased in interstitial fluid $(163 \pm 14$ vs $106 \pm 9 \mathrm{pmol} / \mathrm{l}, p<0.01)$. The halftime for appearance of NN304 in interstitial fluid was slower than human insulin (92 vs $29 \mathrm{~min}$, $p<0.001)$. Yet, equivalency of action was shown for glucose turnover; steady-state glucose uptake $(\mathrm{Rd})$ of $7.28 \pm 0.55$ and $6.76 \pm 0.24 \mathrm{mg} \cdot \mathrm{min}^{-1} \cdot \mathrm{kg}^{-1}$ and en- dogenous glucose production of $0.11 \pm 0.12$ and $0.22 \pm 0.03 \mathrm{mg} \cdot \mathrm{min}^{-1} \cdot \mathrm{kg}^{-1}(p>0.40 ; \mathrm{NN} 304$ and human insulin, respectively). Similar to interstitial fluid, half times for Rd and endogenous glucose production were delayed during NN304 infusion (162 vs $46 \mathrm{~min}$ and 80 vs $31 \mathrm{~min}$, respectively; $p<0.01$ vs human insulin).

Conclusion/interpretation. Firstly equivalency of steady-state action is found at equimolar physiologic infusions of human insulin and NN304. Secondly NN304 binding to plasma albumin results in slower NN304 appearance in the interstitial compartment compared with human insulin. Thirdly the delay in appearance of NN304 in interstitial fluid may not in itself be a source of the protracted action of this insulin analogue. The protracted effect is due primarily to albumin binding of the insulin analogue NN304. [Diabetologia (1999) 42: 1254-1263]

Keywords Fatty acid acylated insulin, glucose turnover, hindlimb lymph, transendothelial transport, albumin binding.
Over the last decade, extensive effort has been dedicated to the development of soluble human insulin analogues with a more prolonged and reproducible

Received: 16 March 1999 and in revised form: 11 May 1999

Corresponding author: M. Hamilton-Wessler, Ph.D., University of Southern California-School of Medicine, Department of Physiology and Biophysics, 1333 San Pablo St., MMR 626, Los Angeles, CA 90033, USA

Abbreviations: NN304, Lys ${ }^{\mathrm{B} 29}$-tetradecanoyl, des-(B30) human insulin; ISF, interstitial fluid; EGP, endogenous glucose production; $\mathrm{Rd}$, glucose uptake; $\mathrm{K}_{\mathrm{a}}$, binding constant; TET, transendothelial transport. action. One approach has been the engineering of fatty acid acylated insulins that have substantial affinity for albumin. In these insulin analogues, the $\varepsilon$-amino group of Lys ${ }^{\mathrm{B} 29}$ is acylated with a saturated fatty acid [1-4]. The acylated insulins bind to albumin at the long- chain fatty acid binding sites, but with a binding constant $\left(\mathrm{K}_{\mathrm{a}}\right)$ lower than that of long-chain fatty acids, i.e. up to $10^{5}$ compared with $10^{7} \mathrm{M}^{-1}$ for longchain fatty acids $[4,5]$. Of several fatty acid acylated insulins tested in pigs Lys ${ }^{\mathrm{B} 29}$-tetradecanoyl des-(B30) human insulin (NN304) was found to be the most protracted compared with native insulin [1]. This analogue, in which a 14-carbon fatty acid (myristic acid) 
is covalently bound to residue $\mathrm{Lys}^{\mathrm{B} 29}$ also showed the maximum binding affinity for albumin. The relatively high albumin binding affinity $\left(\mathrm{K}_{\mathrm{a}}\right.$ of $10^{5} \mathrm{M}^{-1}$ at $\left.37^{\circ} \mathrm{C}\right)$ was hypothesized to account for the protracted effect of NN304 [4]. This human insulin was considered to be a possible candidate for establishing basal insulinaemia in patients with insulinopenic diabetes mellitus. Therefore, to evaluate the peptide's action, it is important to explain its protracted action compared with native insulin.

The action of native insulin has previously been found [6-8] and confirmed [9-11] to be a function of the interstitial fluid insulin concentration. Insulin must traverse the capillary endothelium between plasma and interstitium before binding to insulin receptors at insulin-sensitive tissues. Interstitial insulin concentrations are two to threefold lower and dynamics are considerably slower than in plasma. It has, however, been shown that the interstitial insulin concentration is strongly correlated with glucose turnover [10-11]. Thus, transendothelial transport (TET) has been considered to be a rate-limiting step for insulin action. The question addressed in the present study is whether retention of NN304 in plasma by albumin controls the rate of action of the analogue in vivo. Therefore, our study was undertaken to examine the interstitial fluid profiles and action of an equimolar intravenous infusion of NN304 or human insulin in dogs during euglycaemic clamps.

\section{Materials and methods}

Animals. Experiments were conducted on healthy male mongrel dogs (24.2 $\pm 0.4 \mathrm{~kg}$, range 18.6-31.4 kg). Dogs were housed under controlled kennel conditions (12 h light, $12 \mathrm{~h}$ dark) in the University of Southern California School of Medicine Vivarium. Animals had free access to water and standard chow (24\% protein, 9\% fat, $49 \%$ carbohydrate, $17 \%$ fibre, Wayne Dog Chow, Alfred Mills, Chicago, Ill., USA). Food was withdrawn $18 \mathrm{~h}$ before experiments. The experimental protocols were approved by the University Institutional Animal Care and Use Committee.

Surgical preparation. Surgery was carried out at about 0700 hours. All experiments were done in anaesthetized animals after catheter implantation. Dogs were pre- anaesthetized with acepromazine maleate $(0.22 \mathrm{mg} / \mathrm{kg}$; Prom-Ace; Aueco, Fort Dodge, Iowa, USA) and atropine sulphate (0.11 cc/kg; Western Medical, Arcadia, Calif., USA). Anaesthesia was induced with sodium pentobarbital (Nembutal, $0.44 \mathrm{cc} /$ kg; Abbott Laboratories, Chicago, Ill., USA) and maintained with halothane and nitrous oxide. Indwelling silastic catheters were implanted in the right jugular vein (saline drip), and left carotid artery (sampling). Right and left cephalic vein intracatheters were inserted for tracer, insulin, somatostatin and exogenous glucose infusions as detailed below. A perivascular ultrasonic flowprobe $(2 \mathrm{~mm}$ diameter; Transonic, Ithaca, N. Y., USA) was placed around the right femoral artery for measurement of blood flow. Hindlimb muscle lymphatic fluid [12, 13] was sampled through a polyethylene catheter (PE10 to PE 90, predominantly PE50) inserted into a deep lymph vessel as described previously [11]. Body temperature was maintained with warming pads. Blood pressure, heart rate and respiratory $\mathrm{CO}_{2}$ were monitored continuously. Dogs received a saline drip throughout both the surgery and experiment $(22 \mathrm{cc} / \mathrm{kg}$ given during the first $60 \mathrm{~min}$ of surgery and a slow drip thereafter). Urine was collected throughout the experiment. After experiments, animals were killed by an overdose of sodium pentobarbital (Eutha-6, Western Medical, Arcadia, Calif., USA).

Experimental protocol (NN304 vs human insulin, $n=8$ per group). A total of 16 hyperinsulinaemic euglycaemic clamps were done. In all experiments, after catheter placement, a primed tracer infusion of HPLC-purified, [3- $\left.{ }^{3} \mathrm{H}\right]-\mathrm{D}$-glucose ( $925 \mathrm{kBq}$ bolus followed by $9.25 \mathrm{kBq} / \mathrm{min}$; Dupont-NEN, Boston, Mass., USA) was started and maintained throughout the euglycaemic clamp to assess glucose turnover. Exogenous glucose was labeled with $\left[3-{ }^{3} \mathrm{H}\right]$-D-glucose, $100 \mathrm{kBq} / \mathrm{g}$ of glucose [14] Arterial sampling ( $\sim 3 \mathrm{ml}$ blood) was coupled with hindlimb lymphatic sampling (continuously from $\sim 1.5 \mathrm{~min}$ before to $\sim 1.5$ min after arterial sample time, $300-700 \mu \mathrm{l}$ of lymphatic fluid).

After a 90-min tracer equilibration, four basal samples were taken from -30 to $-1 \mathrm{~min}$. At time 0 , a continuous equimolar $\left(3.6 \mathrm{pmol} \cdot \mathrm{min}^{-1} \cdot \mathrm{kg}^{-1}\right)$ intravenous infusion of either human insulin (Novolin-R, Novo Nordisk, Bagsvaerd, Denmark) or Lys $^{\mathrm{B} 29}$-tetradecanoyl, des-(B30) human insulin (NN304; Insulin Research, Novo Nordisk) was initiated. To suppress endogenous insulin release, a continuous infusion of somatostatin $\left(0.8 \mu \mathrm{g} \cdot \mathrm{min}^{-1} \cdot \mathrm{kg}^{-1}\right.$; Bachem, Torrance, Calif., USA) was also begun at $0 \mathrm{~min}$. Arterial and hindlimb lymph samples for human insulin, NN304, glucose and tracer were collected every $5 \mathrm{~min}$ from 5 to $90 \mathrm{~min}$, then every $10 \mathrm{~min}$ to the end of the experiment at $480 \mathrm{~min}$. In addition, a portion of the arterial sample was taken for non-esterified fatty acids (NEFA).

Assays. Arterial blood samples were collected in ice-chilled Vacutainer tubes containing lithium heparin (Becton Dickinson, Franklin Lakes, N. J., USA). Hindlimb lymph was collected in microtubes pre-coated with lithium heparin (Brinkman Instruments, Westbury, N. Y., USA). Blood and lymph samples were kept on ice until centrifugation. Arterial samples for assay of NEFA were collected with EDTA and Paraoxon (Sigma Immunochemicals, St. Louis, Mo., USA) to inhibit lipoprotein lipase [15]. Plasma and lymph samples were stored at $-20^{\circ} \mathrm{C}$ until assayed. Plasma glucose was assayed immediately by the glucose oxidase method on an automated analyser (Yellow Springs Instrument, Yellow Springs, Ohio, USA). Measurement of $\left[3-{ }^{3} \mathrm{H}\right]$-D-glucose concentration was done as described previously [14]. Determination of NEFA was done with a colorimetric method (NEFA C; Wako Chemicals USA, Richmond, Va., USA).

Insulin and NN304 assays. Human and porcine (identical to canine) insulin were measured in arterial and lymph with an enzyme-linked immunospecific assay (ELISA) for the appropriate insulin (Novo Nordisk) [16].

Total concentrations of NN304 (albumin-bound and unbound) were measured in arterial and lymph using a specific ELISA method developed by Novo Nordisk and adapted in our laboratory. This method uses monoclonal antibodies specific to NN304, which exhibit no measurable cross-reactivity with either human or dog insulin. Monoclonal antibodies against NN304 were immobilized on ELISA plates (MaxiSorp, NUNC, Roskilde, Denmark). Samples and standards (25 $\mu \mathrm{l})$ were then added to the plate wells. The antibody-bound 
NN304 was detected by biotin-labelled monoclonal antibodies against human insulin and ultimately visualized colourimetrically using peroxidase-labelled avidin followed by enzyme substrate TMB. The NN304 concentration in samples was estimated using a standard of NN304 that was prepared in antibodydetecting buffer. The range of the NN304 standard curve was 0-400 pmol/l. Porcine serum spiked with NN304 was used for quality control samples. Absorbance values were read at 450 nm. Softmax (Pharmacia, Biotech, Piscataway, N.J., USA) software was used for transforming absorbances into pmol/l values of NN304. Lower limit of quantification of NN304 was $10 \mathrm{pmol} / \mathrm{l}$, and intra-assay and inter-assay coefficients of variation were $5 \%$ and $9 \%$.

Calcuations. Tracer-determined glucose uptake (Rd) and endogenous glucose production (EGP) were calculated using Steele's model with a labelled glucose infusion [14] after smoothing plasma glucose and tracer data by optimal segments [17]. Steady-state values were calculated by averaging data from the last $2 \mathrm{~h}$ of insulin or NN304 infusion (i.e., 360-480 min). The plasma:ISF ratio was calculated by dividing the steady-state increment above basal for plasma insulin or NN304 by the respective interstitial concentration.

To compare the kinetics of insulin, NN304 and glucose turnover, data from individual experiments were expressed as a percentage of steady-state concentrations (360-480 min). Half-times were then estimated as the time $(\mathrm{min})$ required to reach $50 \%$ of the increment between basal and steady state.

Statistical analysis. Standard statistics (independent and paired Student's $t$ tests), and one-way analysis of variance, ANOVA, [18] with Tukey's procedure were conducted with Minitab (State College, Pa., USA) statistical software on a personal computer. Data are expressed as means \pm SEM and $p$ values of 0.05 or less were considered significant.

\section{Results}

Blood flow. Basal femoral artery blood flow was similar between groups $(162 \pm 12$ vs. $164 \pm 30 \mathrm{ml} / \mathrm{min}$; $p>0.50)$. Blood flow increased from basal during human insulin infusion (mean increase of $25.5 \pm 6.6 \%$, $p<0.05$ vs basal) and during NN304 infusion (mean increase of $29.7 \pm 10.2 \%, p>0.10 \mathrm{vs}$ basal). No statistically significant differences were noted between groups during the clamps $(p>0.50$ at min 120, 240 and 480). Therefore, dynamic differences between groups could not be attributed to blood flow.

Glucose. Basal glucose values under anaesthesia were lower in the control than NN304 group (6.3 \pm 0.2 vs $7.4 \pm 0.3 \mathrm{mmol} / 1, p=0.01)$. During the glucose clamps, however, a similar glucose concentration of $6.5 \pm 0.1 \mathrm{mmol} / 1$ with a $\mathrm{CV}$ of $8.4 \%$ was established among groups $(p>0.10$ for steady state, Fig.1A). Glucose specific activity throughout the clamps did not differ among groups ( $p>=0.50$, Fig. 1B).

Insulin and NN304. At basal in both groups, endogenous plasma insulin exceeded interstitial insulin concentrations (55 \pm 8 and $19 \pm 3 \mathrm{pmol} / \mathrm{l})$. Endogenous in-
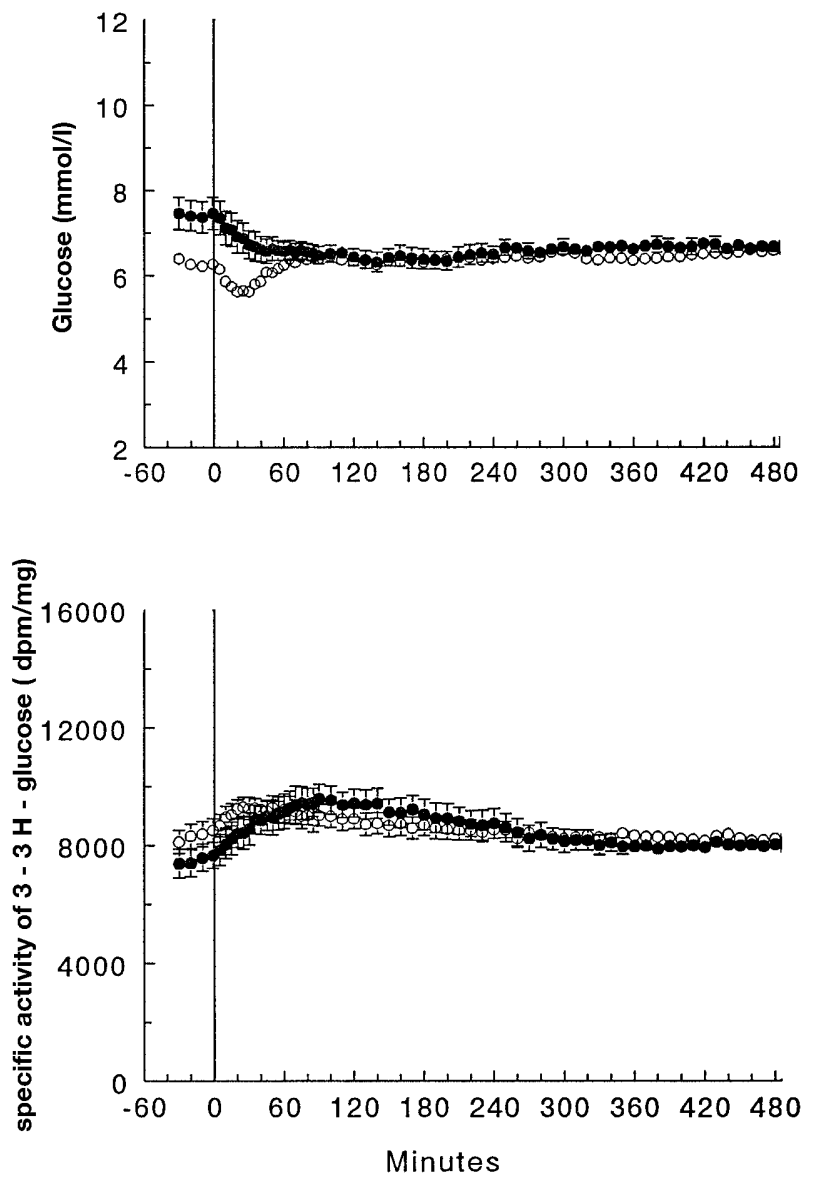

Fig.1A, B. During continuous intravenous infusion (3.6 $\mathrm{pmol} \cdot \mathrm{min}^{-1} \cdot \mathrm{kg}^{-1}$ ) of human insulin $(\bigcirc)$ or insulin analogue NN304 ( ), (A) plasma glucose and (B) glucose specific activity. $n=8$ per group. Data are mean \pm SEM

sulin was suppressed to concentrations which were too low to measure $40 \mathrm{~min}$ after initiation of somatostatin (based on NN304 experiments). During human insulin infusion, plasma and interstitial insulin rose to steady states of $181 \pm 10$ and $106 \pm 9 \mathrm{pmol} / 1$, respectively, (Fig.2A). A steady-state plasma:ISF ratio of $1.7 \pm 0.1$ was established for human insulin. Both basal and steady state plasma:ISF ratios were within ranges reported in the literature [7-11]. With an equimolar NN304 infusion, plasma total NN304 (bound and unbound) reached a steady state of $1895 \pm 127 \mathrm{pmol} / 1$ (Fig. 2B), or ten times higher than was reached with human insulin $(181 \pm 10 \mathrm{pmol} / \mathrm{l})$. In sharp contrast to plasma values, interstitial total NN304 concentrations reached a steady state of $163 \pm 14 \mathrm{pmol} / 1$, or only 1.5 times the insulin concentration during human insulin infusion (106 $\pm 9 \mathrm{pmol} / \mathrm{l})$. Accordingly, the plasma:ISF ratio of $12.0 \pm 1.0$ for $\mathrm{NN} 304$ was much greater than for human insulin.

The NN304 kinetics were significantly slower than human insulin. Plasma half-times were prolonged for NN304 (median of 7 vs 18 min for human insulin vs 


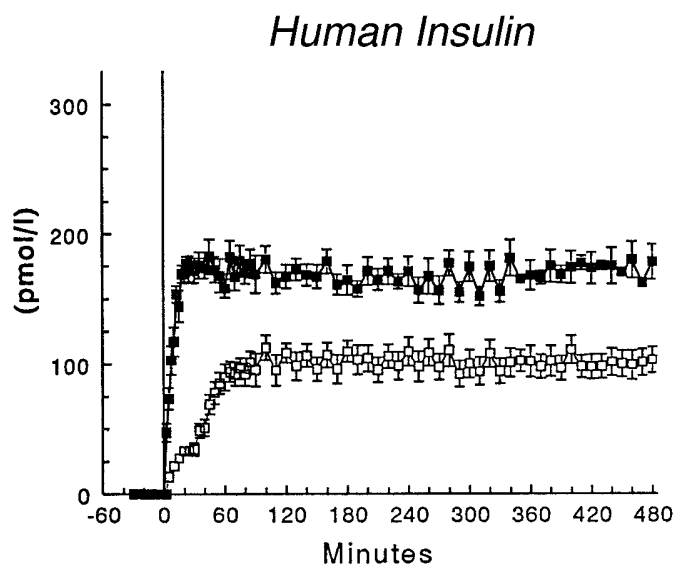

Fig. 2A, B. Plasma ( $\square$ ) and interstitial $(\square)$ dynamics during continuous intravenous infusion $\left(3.6 \mathrm{pmol} \cdot \mathrm{min}^{-1} \cdot \mathrm{kg}^{-1}\right)$ of (A) human insulin or (B) insulin analogue NN304. Values for NN304 are total (bound and unbound) concentrations

NN304, respectively, $p<0.01$; Table 1). A more pronounced delay for NN304 was shown in ISF with a threefold greater half-time (median of 29 vs $92 \mathrm{~min}$ for human insulin vs NN304, respectively, $p<0.01$ ).

Glucose turnover. Despite the large difference in plasma peptide concentrations, steady-state glucose infusion rates were similar for human insulin and NN304 $\left(6.57 \pm 0.24\right.$ vs $7.17 \pm 0.65 \mathrm{mg} \cdot \mathrm{min}^{-1} \cdot \mathrm{kg}^{-1}, p=0.40$ between groups). The time course for the increase in glucose infusion was, however, slower during NN304 than human insulin infusion (Fig. 3A). Basal glucose turnover was similar between control and NN304 groups ( $2.28 \pm 0.14 \mathrm{vs} 2.47 \pm 0.14 \mathrm{mg} \cdot \mathrm{min}^{-1} \cdot \mathrm{kg}^{-1}$, respectively, $p>0.10$ between groups). The equimolar infusion of either human insulin or NN304 increased glucose uptake to similar steady states $(6.76 \pm 0.24$ and $7.28 \pm 0.55 \mathrm{mg} \cdot \mathrm{min}^{-1} \cdot \mathrm{kg}^{-1}, p=0.40$; Fig. 3B). Similar suppression of EGP was also observed with human insulin or NN304 $(0.22 \pm 0.03$ and $0.11 \pm 0.12 \mathrm{mg}$. $\min ^{-1} \cdot \mathrm{kg}^{-1}, p>0.40$ between groups; Fig. 3C).

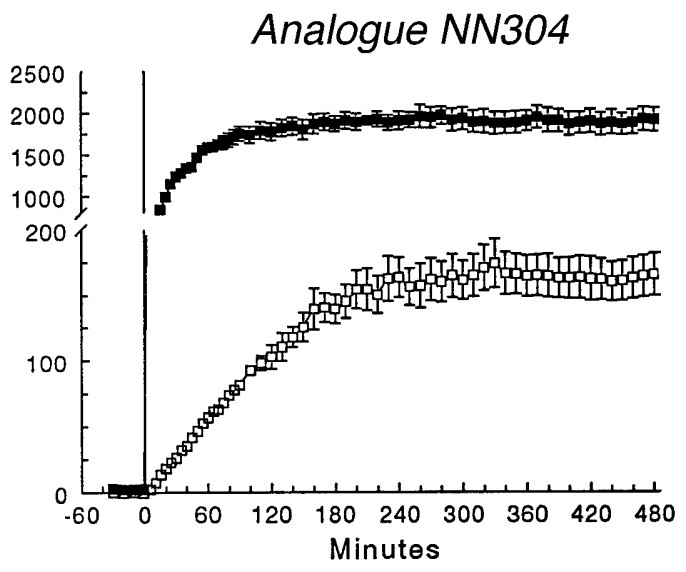

Although steady-state effects were similar, the temporal dynamics differed for glucose turnover during NN304 compared with human insulin infusion (Table 1 and Fig.4). Like insulin and NN304 themselves (Table 1), half-times to steady state for glucose uptake and production were slower with NN304 infusion than with human insulin. In Figure 4, we compare peptides in plasma and ISF with measures of glucose turnover during both insulin and NN304 infusions.

For comparison of dynamics, variables are represented as per cent of steady state (360-480 min). During human insulin infusion (Fig. 4A), plasma insulin reached $100 \%$ of steady state by $27 \pm 4$ min. During NN304 infusion (Fig.4B), plasma NN304 did not achieve $100 \%$ of steady state until $80 \pm 4 \mathrm{~min}$. Despite steady-state plasma concentrations of plasma peptides, ISF peptide, glucose uptake and glucose production were only at or near $50 \%$ of steady state. Thus it is appears from the time curves that glucose turnover follows more closely the dynamics of peptide in ISF rather than of plasma. Plasma half-times were considerably different from the half-times for glucose turnover $(p<0.001$; Table 1$)$ for both human insulin and NN304 infusions. In contrast, ISF halftimes were not different from the half-times for glucose production ( $p>0.50$ for both). The ISF halftimes appeared, however, more rapid than glucose

Table 1. Half-times (time to $50 \%$ of steady state), during human insulin and NN304 infusions $\left(3.6 \mathrm{pmol}^{\prime} \cdot \mathrm{min}^{-1} \cdot \mathrm{kg}^{-1}\right)$, for plasma and interstitial fluid insulin and analogue, glucose uptake, endogenous glucose production and plasma non-esterified fatty acids

\begin{tabular}{|c|c|c|c|c|c|}
\hline Half-time (range), min & $\begin{array}{l}\text { Plasma } \\
\text { Peptide }\end{array}$ & $\begin{array}{l}\text { Interstitial } \\
\text { Peptide }\end{array}$ & $\begin{array}{l}\text { Glucose } \\
\text { Uptake }\end{array}$ & $\begin{array}{l}\text { Glucose } \\
\text { Production }\end{array}$ & NEFA \\
\hline Human Insulin & $\begin{array}{l}7 \\
(3-12)\end{array}$ & $\begin{array}{l}29 \\
(22-36)\end{array}$ & $\begin{array}{l}46 \\
(33-89)\end{array}$ & $\begin{array}{l}31 \\
(24-41)\end{array}$ & $\begin{array}{l}29 \\
(17-47)\end{array}$ \\
\hline
\end{tabular}

Half-time expressed as median and (range). $n=8$ per group. ${ }^{\text {a }}, p<0.01$ vs half-time with human insulin infusion 

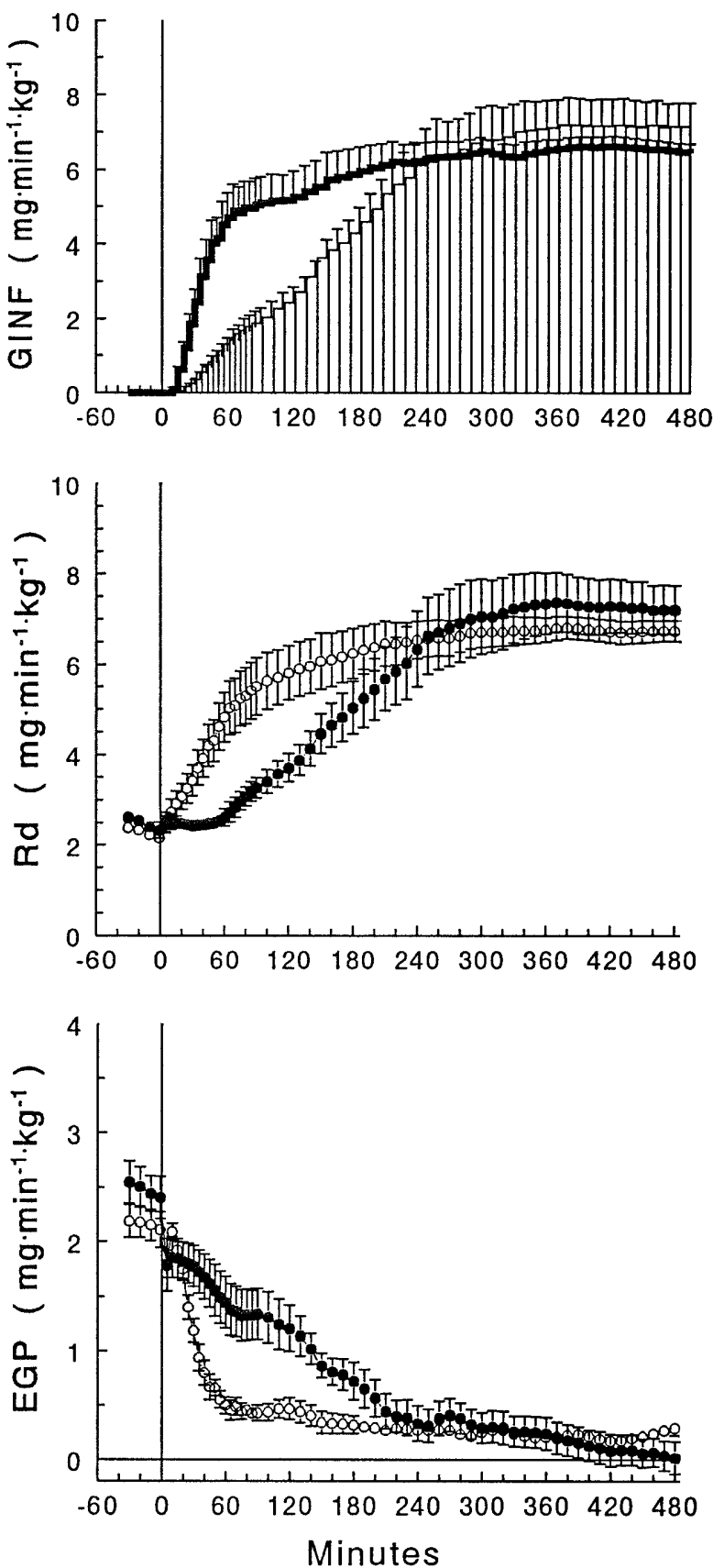

Fig.3A-C. Rate of (A) glucose infusion (GINF) (B) glucose uptake $(\mathrm{Rd})$ and $(\mathbf{C})$ endogenous glucose production (EGP) during continuous equimolar intravenous infusion (3.6 $\mathrm{pmol} \cdot \mathrm{min}^{-1} \cdot \mathrm{kg}^{-1}$ ) of human insulin (solid line for GINF and O) or insulin analogue NN304 (open bar for GINF and O)

uptake half-times for both peptides ( $p=0.05$ for human insulin and $p<0.05$ for NN304).

That the turnover profiles more closely followed ISF dynamics than plasma dynamics was consistent with the finding of a stronger association between ISF concentrations and glucose turnover compared with plasma concentrations of human insulin and NN304 during glucose clamps (Figs. 5 and 6, respectively). During human insulin infusion, there was no-

A

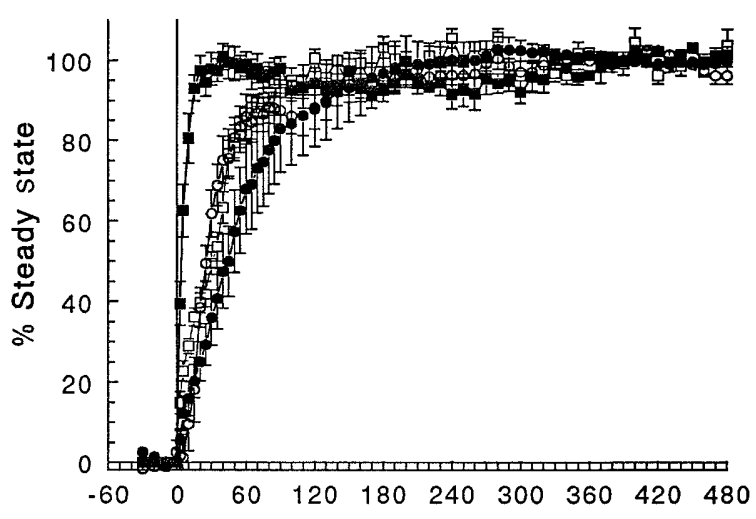

A

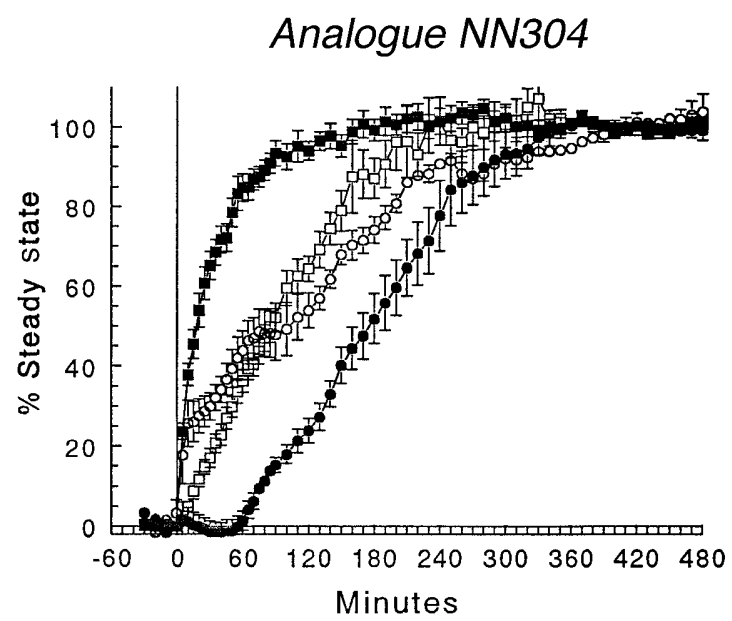

B

Fig. 4A, B. Plasma peptide ( $\square$ ), ISF peptide ( $\square$ ), glucose uptake $(\mathrm{Rd}, \mathbf{O})$ and endogenous glucose production (EGP, $\bigcirc$ ) expressed as a percentage of steady state (360-480 $\mathrm{min})$ during human insulin (A) and NN304 (B) infusion at 3.6 $\mathrm{pmol} \cdot \mathrm{min}^{-1} \cdot \mathrm{kg}^{-1}$. For both human insulin and NN304 infusions, plasma peptide increases quickly whereas ISF insulin, $\mathrm{Rd}$ and EGP increase more slowly ( $p<0.001$ vs plasma halftime). A notable delay occurs for the increase in $\mathrm{Rd}$ during NN304 infusion ( $p<0.05$ vs ISF half-time)

table discontinuity between the relative change in plasma insulin and glucose turnover such that plasma insulin changed much earlier than $\mathrm{Rd}$ or EGP (Fig. 5A and B, respectively). Plasma insulin rose much more rapidly than did the change in glucose uptake (Fig. 5A) and production (Fig. 5B). A closer association was, however, shown for the relative change in ISF insulin and glucose turnover (Fig. 5C and 5D). That is, the association between ISF insulin and glucose turnover more closely approached a linear trajectory. During NN304 infusion, a discontinuity was also noted between the relative change in plasma NN304 and glucose turnover (Fig. 6A and 6B). Some delay in the relative change in glucose uptake compared with ISF was again noted for NN304 (Fig. 6C). A close association was observed, however, between the relative change in ISF analogue and glucose pro- 


\section{Human Insulin}

A
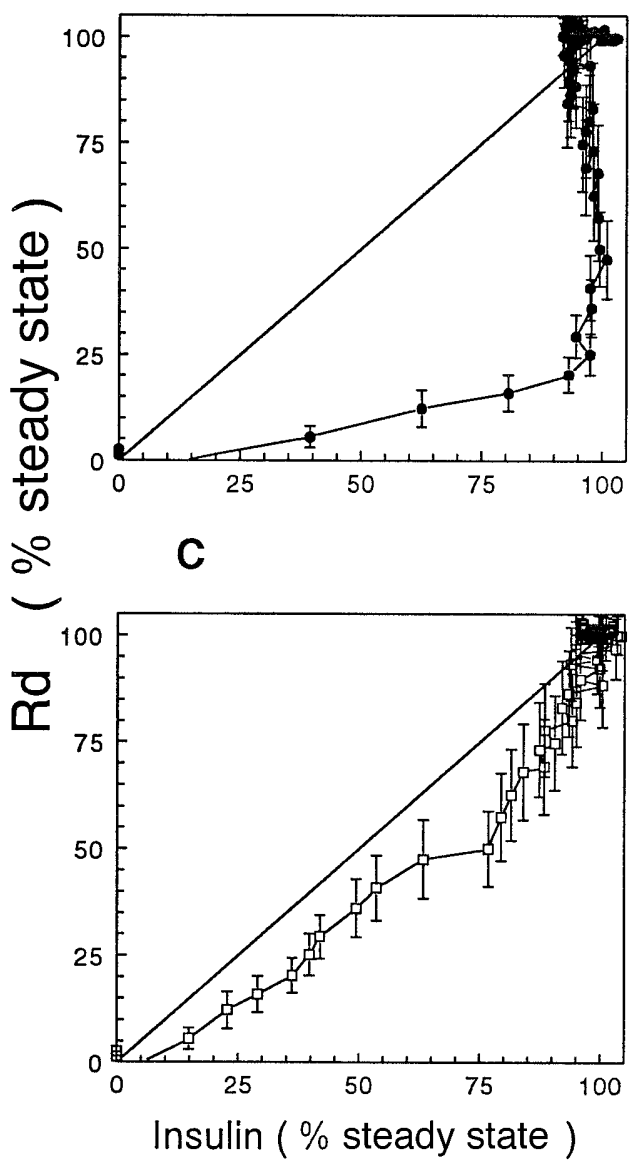

Fig.5A-D. During human insulin infusion, relative change in glucose uptake or $\mathrm{Rd}(\mathbf{A}$ and $\mathbf{C})$ and endogenous glucose production or EGP (B and $\mathbf{D})$ as a function of the relative change in plasma (O) and ISF insulin. Values are expressed as a percentage of steady state (360-480 min). Line denotes one-toone relation for comparison. Discontinuity noted between relative changes in plasma insulin and glucose turnover. Associations between relative changes in ISF insulin and glucose turnover approach one-to-one relations

duction (Fig. 6D). Thus, for NN304, although there was a close association during clamps between EGP and interstitial NN304, Rd rose more slowly than interstitial NN304.

Non-esterified fatty acids. Human insulin and NN304 infusions resulted in nearly total suppression of NEFA from basal $(0.42 \pm 0.03 \mathrm{mmol} / 1)$ to steadystate concentrations of $0.10 \pm 0.01$ and $0.12 \pm$ $0.02 \mathrm{mmol} / 1$, respectively ( $p=0.30$ between groups; $p \leq 0.001$ vs basal; Fig. 7A). The dynamics of NEFA mimicked interstitial, but not plasma, peptide dynamics and were delayed with NN304 compared with hu-
B
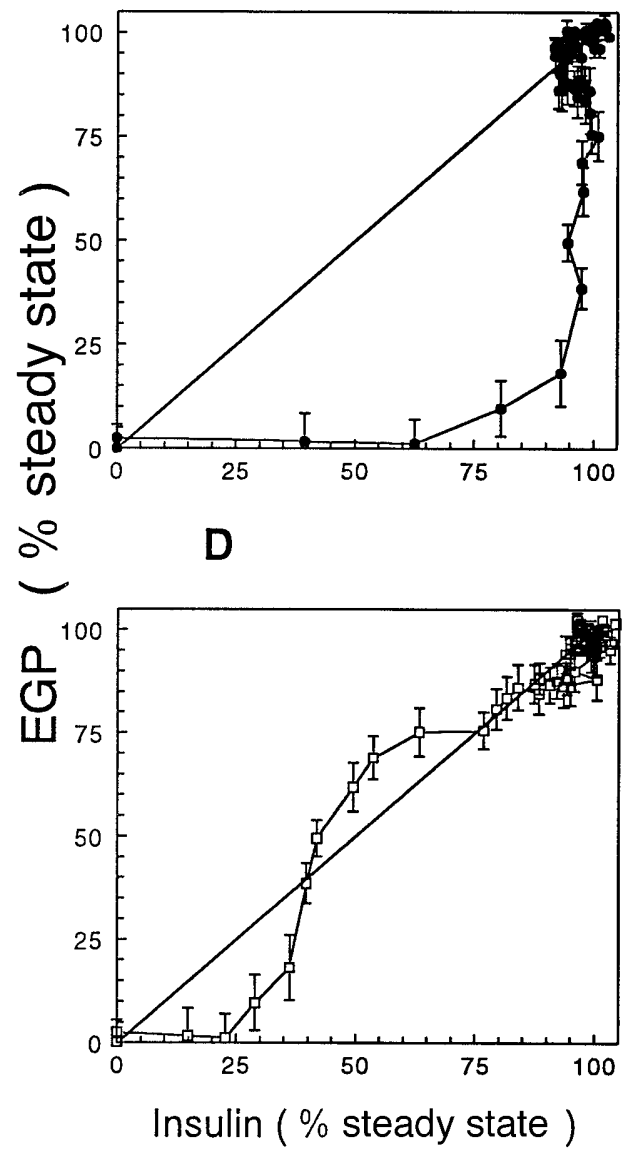

man insulin infusion $(p<0.01$; Table 1). During clamps, a strong association between NEFA and EGP was, however, shown for both human insulin and NN304 infusions $\left(r^{2}=0.89 \pm 0.02\right.$ and $0.81 \pm$ 0.03 , respectively; Fig. 7B). Mean slopes of EGP as a function of NEFA were similar for human insulin and NN304 at $8.46 \pm 1.19$ and $9.26 \pm 2.61 \mathrm{mg} \cdot \mathrm{min}^{-1}$. $\mathrm{kg}^{-1} \cdot \mathrm{mmol} / \mathrm{l}, \quad$ respectively, $\quad(p=0.80$ between groups).

\section{Discussion}

The provision of stable and reproducible basal insulin concentrations has long been a matter of concern in the treatment and management of glucose control in diabetes [19]. To provide a more optimal control of blood glucose, insulin derivatives with affinity for albumin by acylation of the hormone with fatty acids were developed over the last five years [1-4]. These soluble insulins bind to albumin at fatty acid binding sites providing a reservoir of plasma albumin-bound hormone presumably inaccessible to the hepatic insulin receptor when bound. These insulin analogues 


\section{Analogue NN304}

A

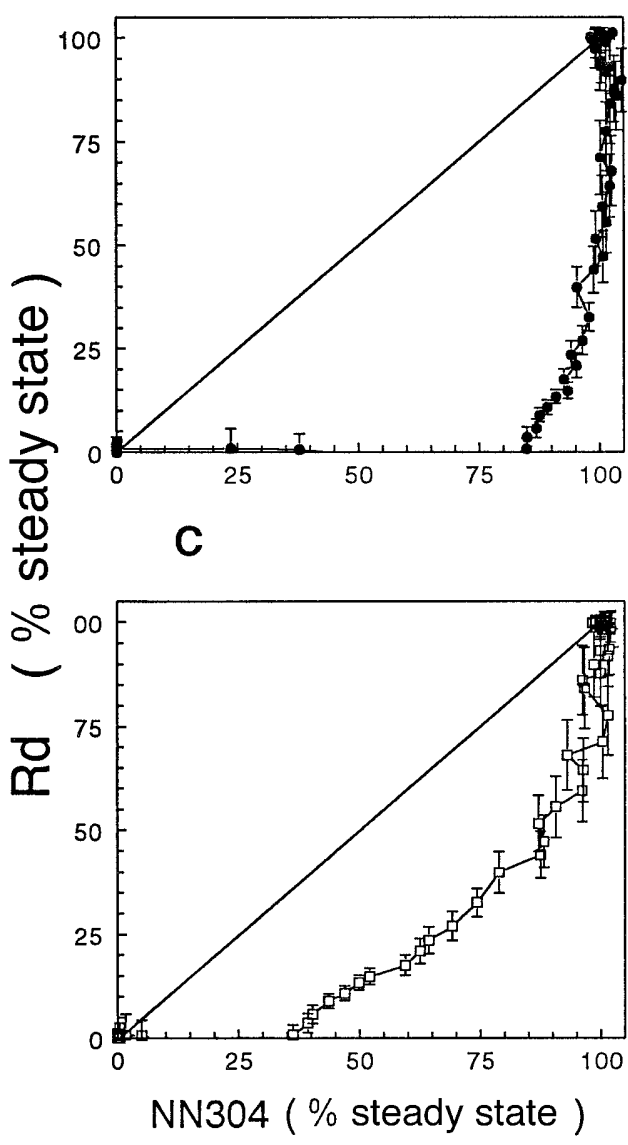

Fig.6A-D. During insulin analogue NN304 infusion, relative change in glucose uptake or $\operatorname{Rd}(\mathbf{A}$ and $\mathbf{C})$ and endogenous glucose production or EGP (B and $\mathbf{D})$ plotted as a function of the relative change in plasma $(\bigcirc)$ and ISF $(\square)$ analogue, NN304. Values are expressed as a percentage of steady state (360-480 $\mathrm{min}$ ). Line denotes one-to-one relation for comparison. Discontinuity noted between relative changes in plasma NN304 and glucose turnover. Association between relative changes in ISF and Rd demonstrate delay in stimulation of glucose uptake. Association between relative changes in ISF and EGP approach a one-to-one relation

have a prolonged action profile compared with native insulin, hypothesized to be due to delayed absorption from the subcutaneous injection site and delayed transendothelial transport due to albumin binding. To date, glucose turnover and interstitial fluid dynamics of the analogues compared with human insulin have not been investigated.

We examined the metabolic effect of $\mathrm{Lys}^{\mathrm{B} 29}$-tetradecanoyl, des-(B30) human insulin (or NN304), during euglycaemic clamps with interstitial fluid sampling. Similar steady states for Rd and EGP achieved with NN304 and human insulin infusions were ob-

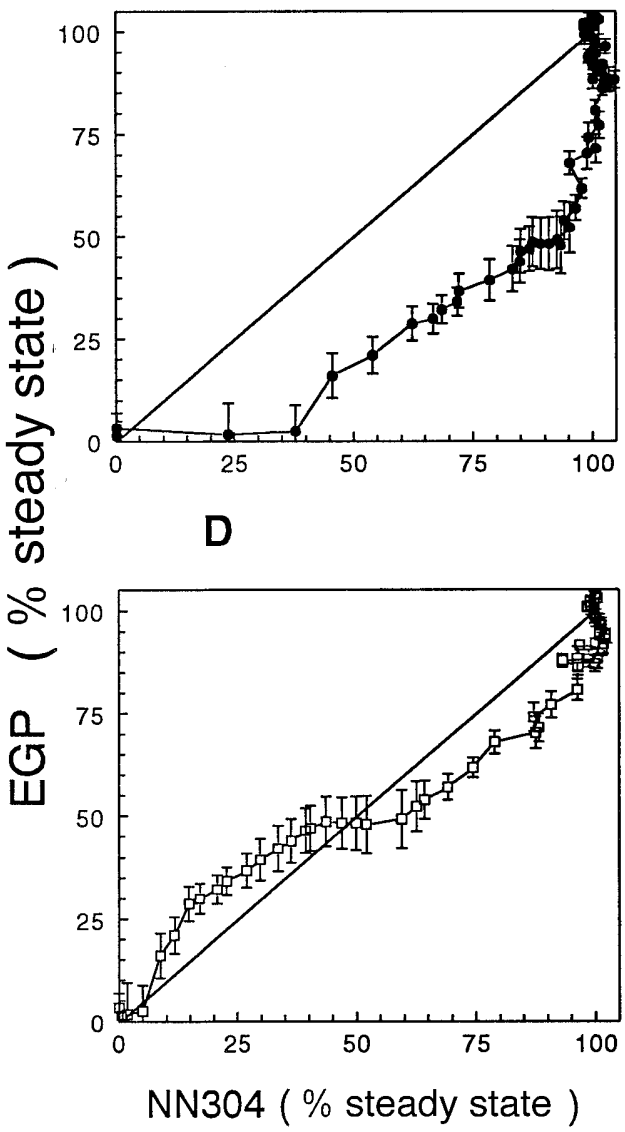

served despite large differences in plasma concentrations and only slightly differing interstitial concentrations. The mean steady state EGP for NN304 was lower than human insulin, however, this did not achieve statistical significance $(p>0.40)$. The possibility of a greater effect of NN304 compared with human insulin on the suppression of glucose production remains to be determined with further study under normal conscious conditions. For NN304, as with native insulin [8-11], the rates of increase in glucose uptake and suppression of endogenous glucose production were determined predominately by the interstitial dynamics, not the plasma dynamics (Fig.4). During both human insulin and NN304 infusions, there was a considerably more rapid half-time for plasma peptide than ISF, Rd and EGP. Thus, similar to native insulin, transcapillary transport is rate-limiting for NN304 action.

The slower dynamics observed for the stimulation of Rd and suppression of EGP during NN304 compared with human insulin infusion suggest that fatty acid acylation of the insulin molecule to promote its binding to albumin has a great influence on the kinetics, or rate, of action. Notably glucose turnover dynamics were profoundly influenced by the delay in 

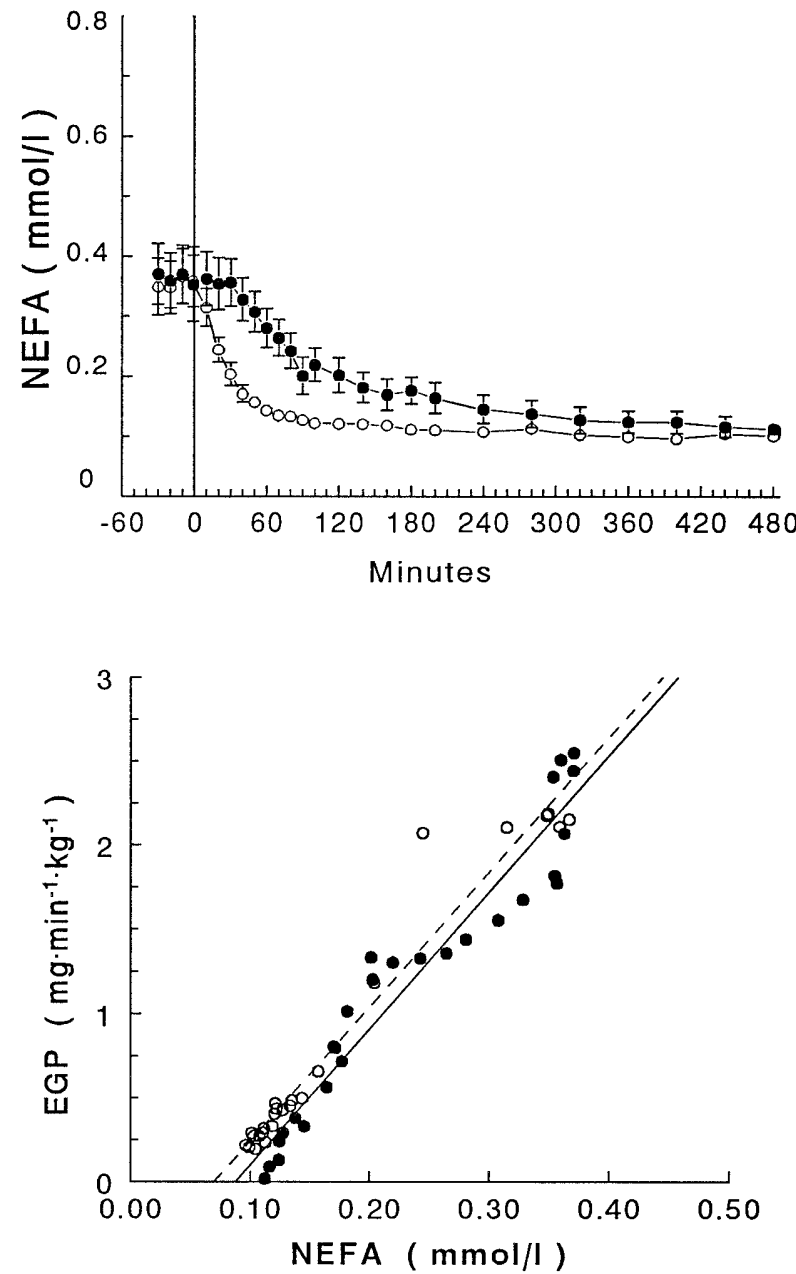

Fig. 7. A Plasma non-esterified fatty acids (NEFA) concentrations during continuous intravenous infusion (3.6 pmol. $\mathrm{min}^{-1} \cdot \mathrm{kg}^{-1}$ ) of human insulin $(\bigcirc)$ or insulin analogue NN304 (O). B Mean endogenous glucose production (EGP) plotted as a function of NEFA concentration with human insulin and NN304 infusions

the appearance of NN304 in interstitial fluid. Glucose uptake and production curves (Fig. 3 and Fig.4B) were slowed with about threefold increases in the half-times to steady state during NN304 infusion compared with human insulin (Table 1). Thus it appears that retention of NN304 in plasma by binding to fatty acid binding sites on albumin retards the action of the analogue compared with native insulin by delaying the appearance of NN304 in interstitial fluid and consequently delaying the action at insulin sensitive tissues.

It is notable that the half-times for glucose uptake during both human insulin and NN304 infusions were not identical to the interstitial half-times (Table 1, Figs. $5 \mathrm{C}$ and 6C). Previous work from our laboratory $[11,20]$ and others $[10,21]$ has provided ranges for the half-times for $\mathrm{Rd}(15-71 \mathrm{~min})$ and for EGP (8-65 min). Thus, the observed shift in the Rd half- time relative to ISF with human insulin infusion, although within the previous reported ranges, may have been a consequence of the experimental protocol and methodology. The stronger association between changes in glucose turnover and interstitial peptide, however, remains.

With NN304 infusion, the half-times persisted longer for ISF and for glucose turnover than with human insulin. The half-time for Rd was noticeably delayed compared with the ISF and EGP half-times (Table 1, Fig. 6). These data suggest that the kinetics of NN304 action at the adipocyte are more congruous to the ISF profile than at skeletal muscle. It is apparent from this data that the action of the analogue is more closely associated with the analogue profile in interstitial fluid than with plasma; there is, however, an apparent further delay in NN304 action to stimulate glucose uptake in peripheral tissue. This extra delay could be related to a slow dissociation of NN304 from albumin and insulin receptor binding. Alternatively, there could be an extra delay in insulin signalling or glucose transporter recruitment with this insulin analogue.

The metabolic effects of NN304 to suppress endogenous glucose production and non-esterified fatty acids during NN304 infusion followed similar kinetics, albeit slower than for human insulin, that were closely related to interstitial fluid dynamics (Fig.7 and Table 1). A strong linear association between glucose production and free fatty acids was observed in this study, indicating an association between the suppression of lipolysis and of glucose production. This phenomenon has been extensively examined for native insulin, resulting in the "Single Gateway Hypothesis" [22]. This hypothesis suggests that the lowering of circulating non-esterified fatty acids by the suppression of lipolysis at the adipocyte is the signal for insulin's suppression of glucose production. Our findings support this hypothesis and indicate that it can be extended to NN304 action. Thus, NN304 appears to act by the suppression of lipolysis, or NEFA, to suppress endogenous glucose production. Moreover, we have shown that, under normal conditions, the suppression of lipolysis and of EGP tend to follow peripheral interstitial dynamics, rather than plasma dynamics. These findings are consistent with the concept that peripheral interstitial peptide concentrations, rather than circulating plasma concentrations, determine the rate and extent of suppression of lipolysis and EGP.

At steady state during clamps, the concentration of NN304 in plasma greatly exceeded that of native insulin (ratio 10:1, Figure 2), despite similar infusion rates. It is known that in vitro, when exposed to albumin, the great proportion (96-98\%) of NN304 is bound to albumin, apparently protecting the bound analogue from liver degradation, and achieving a high steady state concentration in plasma. In sharp 
contrast to the plasma compartment, in ISF, at steady state the total concentrations of NN304 and insulin were more similar (163 vs $106 \mathrm{pmol} / \mathrm{l})$. In addition, at steady state, the effects of the two compounds upon glucose uptake were likewise similar $(7.28 \pm 0.55$ vs $\left.6.76 \pm 0.24 \mathrm{mg} \cdot \mathrm{min}^{-1} \cdot \mathrm{kg}^{-1}\right)$. In vitro, the $\mathrm{K}_{\mathrm{a}}$ value for NN304 favours the bound moiety $\left(\mathrm{K}_{\mathrm{a}}\right.$ of $10^{5}$. $\mathrm{M}^{-1}$ ). If this association constant applies in vivo, in ISF in which the albumin concentration is approximately $0.3 \mathrm{mmol} / 1[23,24)$, the free concentration of NN304 would be much lower than the invariably free concentration of native insulin (e.g. 6 vs 106 $\mathrm{pmol} / \mathrm{l}$, respectively). How then is it possible that such a small apparently unbound concentration of NN304 can have the same effect on glucose uptake as native insulin in the interstitial compartment?

The phenomenon of a bound moiety having greater apparent bioactivity than would be calculated assuming equilibrium binding has been reported previously for various ligands. Several explanations have been suggested for this phenomenon. For example, the active "sequestering" of a protein- bound ligand by target tissue has been described [25, 26]. By this model, the insulin receptors themselves would bind and internalize NN304 accessed directly from the albumin-NN304 complex [27, 28]. A second concept follows from reports of influx into tissue of non-esterified fatty acids or steroids exceeding both the expected rates of dissociation of bound complexes (to albumin or steroid binding proteins, respectively) and what would be expected from equilibrium kinetics. It has been suggested that dissociation of NEFA from albumin is mediated by a specific albumin receptor on the plasma membrane which binds albumin and "delivers" the ligand to the receptor [29]. Alternatively, it has been suggested that albumin associates with the cell surface resulting in a conformational change in albumin and a reduction in the apparent affinity constant for the albumin-ligand complex, which enhances binding of the ligand to its receptor $[30,31]$.

Whether one accepts the conventional theory [25, 26], receptor hypothesis [29] or inhibitor hypothesis $[30,31]$, it is apparent that NN304 cellular uptake and action at skeletal muscle and adipose in vivo are proportional to the rate of dissociation of NN304 from albumin and insulin receptor binding and activation, rather than the interstitial NN304 concentration (bound and unbound). These data appear to indicate that equilibrium kinetics do not apply for NN304 in the interstitium; i.e. the biologically effective concentration clearly exceeds the concentration ( $2 \%$ of total) that one might expect based upon equilibrium relations.

In summary, equimolar intravenous infusions of the fatty acid acylated insulin, NN304, and human insulin result in equivalent steady-state action. Yet pronounced slowing in the time profiles for stimulation of glucose uptake and suppression of glucose production occurs with NN304 compared with human insulin. The protracted glucose turnover profiles during NN304 infusion are associated with the slowed appearance of NN304 in interstitial fluid, reflecting a mechanism of protraction of NN304 action. Thus, similar to native insulin, transcapillary transport of NN304 is rate-limiting for its action and it is apparent that retention of the compound by plasma albumin has a controlling influence on the rate of NN304 action in vivo and is possibly the primary mechanism of protraction of NN304 action.

Acknowledgements. The authors thank Dr. M. Loftagger and L. R. Minassian for technical assistance and Dr. J.H. Youn for helpful comments in the preparation of the manuscript.

This work was supported by grants from Novo Nordisk A/S and the National Institutes of Health (DK-29867). M. Hamilton-Wessler was supported by a post-doctoral National Institute of Aging Training Grant Fellowship (AG00093-15). M. Ader was supported by a National Institutes of Health grant (AG-00544). M. Dea was supported by a pre-doctoral National Institute of Aging Training Grant Fellowship (AG00093-15).

\section{References}

1. Markussen J, Havelund S, Kurtzhals P et al. (1996) Soluble, fatty acid acylated insulins bind to albumin and show protracted action in pigs. Diabetologia 39: 281-288

2. Kurtzhals P, Havelund S, Jonassen I, Kiehr B, Pibel U, Markussen J (1996) Albumin binding and time action of acylated insulins in various species. J Pharm Sci 85: 304-308

3. Myers SR, Yakubu-Madus FE, Johnson WT et al. (1997) Acylation of human insulin with palmitic acid extends the time action of human insulin in diabetic dogs. Diabetes 46: 637-642

4. Kurtzhals P, Havelund S, Jonassen I et al. (1995) Albumin binding of insulin acylated with fatty acids: characterization of the ligand-protein interaction and correlation between binding affinity and timing of the insulin effect in vivo. Biochem J 312: 725-731

5. Carter DC, Ho JX (1994) Structure of serum albumin. Adv Protein Chem 45: 153-203

6. Yang YJ, Hope ID, Ader M, Bergman RN (1989) Insulin transport across capillaries is rate limiting for insulin action in dogs. J Clin Invest 84: 1620-1628

7. Ader M, Poulin RA, Yang YJ, Bergman RN (1992) Dose response relationship between lymph insulin and glucose uptake reveals enhanced insulin sensitivity of peripheral tissues. Diabetes 41: 241-253

8. Castillo C, Bogardus C, Bergman RN, Thuillez P, Lillioja S (1994) Interstitial insulin concentrations determine glucose uptake rates but not insulin resistance in lean and obese man. J Clin Invest 93: 10-16

9. Jansson PE, Fowelin JP, Von Schenck HP, Smith UP, Lonnroth PN (1993) Measurement by microdialysis of the insulin concentration in subcutaneous interstitial fluid: Importance of the endothelial barrier for insulin. Diabetes 42: 1469-1473

10. Miles PDG, Levisetti M, Reichart D, Khoursheed M, Moossa AN, Olefsky JM (1995) Kinetics of insulin action in vivo: Identification of rate-limiting steps. Diabetes 44: 947-953 
11. Poulin RA, Steil GM, Moore DM, Ader M, Bergman RN (1994) Dynamics of glucose production and uptake are more closely related to insulin in hindlimb lymph than in thoracic duct lymph. Diabetes 43: 180-190

12. Castillo CE, Lillioja S (1991) Peripheral lymphatic cannulation for physiological analysis of interstitial fluid compartment in humans. Am I Physiol 261:H1324-H1328

13. Renkin EM (1979) Lymph as a measure of the composition of interstitial fluid. In: Fishman AP, Renkin EM (eds) Pulmonary Edema. Am Physiol Society, Bethesda, pp 145-159

14. Finegood DT, Bergman RN, Vranic M (1987) Estimation of endogenous glucose production during hyperinsulinemic-euglycemic glucose clamps: comparison of unlabeled and labeled exogenous glucose infusates. Diabetes 36: 914-924

15. Zambon A, Hashimoto SI, Brunzell JD (1993) Analysis of techniques to obtain plasma measurement of levels of free fatty acids. J Lipid Res 34: 1021-1028

16. Andersen L, Dinesen B, Jorgensen PN, Poulsen F, Roder ME (1993) Enzyme immuncassay for intact human insulin in serum or plasma. Clin Chem 39: 578-582

17. Finegood DT, Bergman RN (1983) Optimal segments: a method for smoothing tracer data to calculate metabolic fluxes. Am J Physiol 244:E472-E479

18. Zar JH (1984) Biostatistical Analysis. Prentice-Hall, New Jersey

19. Galloway JA, Chance RE (1994) Improving insulin therapy: achievements and challenges. Horm Metab Res 26: 591-598

20. Bradley DC, Poulin RA, Bergman RN (1993) Dynamics of hepatic and peripheral insulin effects suggest common ratelimiting step in vivo. Diabetes 42: 296-306

21. Prager R, Wallace P, Olefsky JM (1986) In vivo kinetics of insulin action on peripheral glucose disposal and hepatic glucose output in normal and obese subjects. J Clin Invest 78: 472-481

22. Bergman RN (1997) New concepts in extracellular signaling for insulin action: The single gateway hypothesis. Recent Prog Horm Res 52: 359-387

23. He XM, Carter DC (1992) Atomic structure and chemistry of human serum albumin. Nature 358: 209-215

24. Spector AA (1975) Fatty acid binding to plasma albumin. J Lipid Res 16: 165-179

25. Rowland M, Tozer TN (1995) Clinical Pharmacokinetics: concepts and applications. Lea and Febiger, Philadelphia

26. Sorrentino D, Robinson RB, Kiang C-L, Berk PD (1989) At physiologic albumin/oleate concentrations oleate uptake by isolated hepatocytes, cardiac myocytes, and adipocytes is a saturable function of the unbound oleate concentration: uptake kinetics are consistent with the conventional theory. J Clin Invest 84: 1325-1333

27. Baldwin D Jr, Prince M, Marshall S, Davies P, Olefsky JM (1980) Regulation of insulin receptors: evidence for involvement of an endocytotic internalization pathway. Proc Natl Acad Sci USA 77: 5975-5958

28. Sonne O (1988) Receptor-mediated endocytosis and degradation of insulin. Physiol Rev 68: 1129-1196

29. Stremmel W (1989) Transmembrane transport of fatty acids in the heart. Mol Cell Biochem 88: 23-29

30. Pardridge WM, Landaw EM (1984) Tracer kinetic model of blood-brain barrier transport of plasma protein-bound ligands: empiric testing of the free hormone hypothesis. J Clin Invest 74: 745-752

31. Weisiger RA (1985) Dissociation from albumin: a potentially rate-limiting step in the clearance of substances by the liver. Proc Natl Acad Sci USA 82: 1563-1567 